\title{
Aripiprazole in the treatment of Huntington's disease: a case series
}

\author{
Andrea Ciammola' \\ Jenny Sassone' \\ Clarissa Colciago' \\ Niccolò E Mencacci' \\ Barbara Poletti' \\ Andrea Ciarmiello ${ }^{2}$ \\ Ferdinando Squitieri ${ }^{3}$ \\ Vincenzo Silani' \\ 'Department of Neurology \\ and Laboratory of Neuroscience, \\ "Dino Ferrari" Centre, University \\ of Milan Medical School - IRCCS \\ Istituto Auxologico Italiano, Milano, \\ Italy; ${ }^{2}$ Unit of Nuclear Medicine, \\ S. Andrea Hospital, La Spezia, \\ Italy; ${ }^{3}$ Neurogenetics Unit, IRCCS \\ Neuromed, Pozzilli (IS), Italy
}

\begin{abstract}
Objectives: The aim of the study was to describe the effects of aripiprazole, a new atypical antipsychotic drug that acts as a partial dopamine agonist on motor, behavioral and cognitive functions in patients with genetically confirmed Huntington's disease (HD).

Methods and results: Three HD patients were evaluated for Unified Huntington Disease Rating Scale part I and II and Beck Depression Inventory at baseline, after two months and one-year treatment. Aripiprazole effectively controlled involuntary movements and psychiatric symptoms, with effects on cognitive functions.

Conclusions: Our case reports suggest that aripiprazole is well tolerated, remarkably improving some of the motor and behavioral symptoms in patients affected by HD. Randomized, controlled, long-term studies are warranted.
\end{abstract}

Keywords: Huntington's disease, aripiprazole, treatment, chorea

\section{Introduction}

Huntington's disease (HD) is an autosomal dominant neurodegenerative disorder caused by the expansion of a CAG trinucleotide repeat in the IT-15 gene on the short arm of chromosome 4. The classic HD presentation includes midlife onset of dementia, personality disorders, and chorea. Dystonia and parkinsonism usually become evident later, during the course of the disease. The mainstay therapy for controlling the choreic disorder in HD is based on antidopaminergic agents. ${ }^{1,2}$ Nevertheless classic antipsychotics may induce extrapyramidal symptoms and cognitive slowing down that increase functional disability. ${ }^{3}$ Several studies suggest that atypical neuroleptics, mainly risperidone and olanzapine, having a lower rate of neurological side-effects than typical neuroleptics, could be useful in improving chorea and psychiatric symptoms in HD patients. ${ }^{4-10}$ However, recent reports have raised concerns about a possible association between atypical antipsychotic drugs and adverse metabolic changes. ${ }^{11}$

Aripiprazole, a new second-generation antipsychotic agent, acts as a partial agonist on dopaminergic $\mathrm{D}_{2}$ and serotoninergic $5 \mathrm{HT}_{1 \mathrm{~A}}$ receptors and as antagonist on the $5 \mathrm{HT}_{2 \mathrm{~A}}$ receptors. ${ }^{12,13}$ The use of aripiprazole for the treatment of neurological and/or psychiatric conditions is disclosed in WO/2008/038003 that includes statements indicating the potential usefulness of this drug in Huntington's disease. Owing to its peculiar neuropharmacological profile, aripiprazole is well tolerated, rarely inducing extrapyramidal and metabolic adverse effects when used in schizophrenic patients. ${ }^{14,15}$

In this paper, we report a series of three patients with genetically confirmed HD in whom aripiprazole effectively controlled involuntary movements and psychiatric symptoms with effects on cognitive functions. 


\section{Case reports}

\section{Clinical assessment}

To quantify the effectiveness of aripiprazole in controlling the movement disorder, the following categories of the Unified Huntington's Disease Rating Scale (UHDRS) part I were separately analyzed: oculomotor function (ocular pursuit, saccade initiation, saccade velocity); hyperkinesias (chorea, dystonia, tongue protrusion, and dysarthria); fine motor tasks (finger taps, pronate/supinate hands, Luria test); parkinsonism (rigidity and bradykinesia); and gait (gait, tandem walking, retropulsion test). ${ }^{16}$ Cognitive function was assessed with the UHDRS part II. ${ }^{16}$ Behavioral changes were assessed with the Beck Depression Inventory (BDI). ${ }^{17}$ The baseline and the follow-up visits (after two months and one year treatment) were made by the same neurologist (A.C.). Clinical assessments are reported in Table 1. The patients and their families gave permission to use these data for research.

\section{Case I}

A 56-year-old man carrying a $47 \mathrm{CAG}$ repeat mutation, began in 2001 to experience a progressive choreic disorder and depression, so antidepressant treatment with sertraline $(50 \mathrm{mg} /$ day $)$ was started. Five years later, when his movement disorder led to social embarrassment and difficulties at work, he started neuroleptic treatment first with risperidone $(2 \mathrm{mg} /$ day) switched six months later to olanzapine ( $5 \mathrm{mg} /$ day). Unfortunately, both treatments caused adverse side effects (apathy and depression on risperidone and a severe metabolic syndrome with hepatosteatosis on olanzapine treatment), therefore both drugs were stopped. After a one-month washout period, neurological assessment was conducted and aripiprazole was then started at a dose of $2.5 \mathrm{mg} /$ day, and increased to $7.5 \mathrm{mg} /$ day over two months. Selective serotonin reuptake inhibitors (SSRI) treatment remained unchanged during the whole time of evaluation. Two months later the patient had achieved good control of hyperkinesias, with no evidence of side effects or extrapyramidal adverse events. The caregiver reported that the patient's interest in home and work activities had improved.

After the one-year treatment, neurological examination confirmed the benefit of aripiprazole, and the patient reported no adverse effects. Cognitive function also slightly improved (UHDRS part II total score at baseline $=89.2$ and after 1 year $=98.2$ ) and the patient's BDI scores showed a significant improvement in depression (12 at baseline and 5 after 1 year). The hematological follow-up assessment showed that the metabolic syndrome had almost been resolved, and hepatosteatosis markedly improved.

This case report has had some of its data previously published as part of a conference proceedings. ${ }^{18}$

\section{Case 2}

A 68-year-old woman with a genetically confirmed diagnosis of HD (46 CAG repeats) was referred to our Department in December 2006. She had a 10-15-year history of progressive choreiform movements and behavioral changes. She progressively became dependent on caregivers for performance of all activities of daily living (ADLs). Olanzapine ( $5 \mathrm{mg}$ /day) and lorazepam ( $1.5 \mathrm{mg} /$ day at bedtime) were started in 2005 to treat chorea and behavioral symptoms, initially resulting in good control of behavioral (agitation, anxiety, and insomnia) and motor symptoms. Within one year the benefit waned

Table I Clinical parameters of Huntington's disease patients treated with aripiprazole

\begin{tabular}{|c|c|c|c|c|c|c|c|c|c|c|c|c|}
\hline \multirow[t]{2}{*}{ Patient } & \multirow[t]{2}{*}{ Daily dose } & \multicolumn{3}{|c|}{ Total motor score } & \multicolumn{5}{|c|}{ Oculomotor function } & \multicolumn{3}{|c|}{ Hyperkinesias } \\
\hline & & Baseline & Two months & One year & Baseline & \multicolumn{2}{|c|}{ Two months } & \multicolumn{2}{|c|}{ One year } & Baseline & Two months & One year \\
\hline Case I & $7.5 \mathrm{mg}$ & 50 & $26(-48 \%)$ & $28(-44 \%)$ & 9 & & $6 \%)$ & $4(-$ & $6 \%)$ & 25 & II (-56\%) & $10(-60 \%)$ \\
\hline Case 2 & $15 \mathrm{mg}$ & 112 & $96(-14 \%)$ & $98(-13 \%)$ & 24 & 24 & & 24 & & 51 & $35(-31 \%)$ & $37(-27 \%)$ \\
\hline Case 3 & $7.5 \mathrm{mg}$ & 97 & $6 \mathrm{I}(-37 \%)$ & $64(-34 \%)$ & 23 & 16 & $-30 \%)$ & 17 & $26 \%)$ & 43 & $21(-51 \%)$ & $23(-46 \%)$ \\
\hline \multicolumn{4}{|c|}{ Fine motor tasks } & \multicolumn{5}{|c|}{ Parkinsonism } & \multicolumn{3}{|l|}{ Gait } & \\
\hline Baseline & \multicolumn{2}{|c|}{ Two months } & One year & Baseline & \multicolumn{2}{|c|}{ Two months } & \multicolumn{2}{|c|}{ One year } & \multicolumn{2}{|c|}{ Baseline } & Two months & One year \\
\hline 9 & \multicolumn{2}{|l|}{$5(-44 \%)$} & $7(-22 \%)$ & 3 & \multicolumn{2}{|l|}{3} & \multicolumn{2}{|l|}{3} & \multicolumn{2}{|l|}{4} & $3(-25 \%)$ & 4 \\
\hline 20 & \multicolumn{2}{|l|}{20} & 20 & 5 & \multicolumn{2}{|l|}{5} & \multicolumn{2}{|l|}{5} & \multicolumn{2}{|l|}{12} & 12 & 12 \\
\hline 19 & \multicolumn{2}{|c|}{$14(-26 \%)$} & $14(-26 \%)$ & 4 & \multicolumn{2}{|l|}{4} & 4 & & 8 & & $6(-25 \%)$ & $6(-25 \%)$ \\
\hline
\end{tabular}

To quantify the effectiveness and possible adverse effects of aripiprazole treatment, total motor score and the following categories of the Unified Huntington's Disease Rating Scale (UHDRS) part I were separately analyzed: oculomotor function (ocular pursuit, saccade initiation, saccade velocity), hyperkinesias (chorea, dystonia, tongue protrusion and dysarthria), fine motor tasks (finger taps, pronate/supinate hands, Luria test), parkinsonism (rigidity and bradykinesia), and gait (gait, tandem walking, retropulsion test). UHDRS scores at baseline (left column), after two months (central column) and one year (right column) aripiprazole treatment are reported. 
and increasing the olanzapine dose (up to $15 \mathrm{mg}$ ) failed to induce further benefits.

On admission to our department, the patient was in a wheelchair and her speech was mostly incomprehensible. She had severe upper limb choreathetosis, involuntary facial muscle and tongue movements with severe dysphagia. Olanzapine was tapered and neurological assessment was performed after a washout period of 15 days. Aripiprazole was then started at a dose of $5 \mathrm{mg}$ /day and increased to $15 \mathrm{mg}$ /day over two months. By the second month of treatment, UHDRS subtotal hyperkinesias score decreased from 51 to 35 . Notably, as choreic tongue movements decreased, dysphagia also improved. The caregivers reported an improvement in the quality of both sleep and diurnal agitation. Clinical follow-up after the one-year treatment confirmed good control of motor symptoms without adverse effects. Cognitive and psychiatric assessment in this patient was not possible due to severe cognitive dysfunctions encompassing severe impairment of attention, oral comprehension and executive functions.

\section{Case 3}

The patient, a 68-year-old woman diagnosed 10 years previously with $\mathrm{HD}$ (45 CAG repeats), was referred to our department in 2001. She had severe chorea, dystonic posture, gait difficulties, and moderate dysarthria. She was partially dependent on the caregiver for ADLs. On admission to our department and during the period of the study she was taking paroxetine $20 \mathrm{mg} /$ day. To treat the movement disorder aripiprazole was started in December 2006 and gradually titrated up to $7.5 \mathrm{mg}$ daily. After the patient received $5 \mathrm{mg}$ /day, her choreic movements began to improve. After two months of aripiprazole $7.5 \mathrm{mg}$ /day, the UHDRS hyperkinesias score markedly improved (from 43 to 21). The patient remained stable during the 12-month treatment and reported no side effects. Furthermore we observed a moderate improvement in cognitive assessment (UHDRS part II total score at baseline $=49.7$ and after 1 year $=69.7$ ) and a significant improvement in depression (BDI score at baseline $=24$ and after 1 year $=15$ ). Anxiety also came under acceptable control.

\section{Discussion}

This is to our knowledge the first report describing the beneficial symptomatic effects of the novel antipsychotic drug aripiprazole on motor, psychiatric, and cognitive symptoms in three patients affected by HD. The mechanism through which aripiprazole acted to improve patients' chorea remains elusive. Aripiprazole is a dopamine neurotransmitter stabilizer acting as a functional antagonist in hyperdopaminergic and, conversely, as a functional agonist in hypodopaminergic states. ${ }^{19,20}$ In our small cohort of patients, the drug may have controlled the involuntary movements related to $\mathrm{HD}$ by antagonizing striatal $\mathrm{D}_{2}$ and $\mathrm{D}_{3}$ receptors. $^{21}$

In agreement with several reports, ${ }^{14,15,22}$ aripiprazole also protected our patients from extrapyramidal side effects, probably owing to its pharmacodynamic profile - ie, partial agonist on dopaminergic $\mathrm{D}_{2}$ and on serotoninergic $5 \mathrm{HT}_{1 \mathrm{~A}}$ receptors and antagonist on the $5 \mathrm{HT}_{2 \mathrm{~A}}$ receptors - reducing the antagonist load at the nigrostriatal pathway level. ${ }^{12,13}$ Notably, the improvement in apathy, anxiety, and depression could depend on aripiprazole's action in modulating central serotoninergic pathways. ${ }^{23-25}$

Our report also underlines another advantage of aripiprazole. In the first patient we treated in this series, switching to aripiprazole resolved the possible olanzapine-induced metabolic dysfunction. In agreement with our findings, previous reports have suggested that the risk of metabolic dysfunction is reduced in patients treated with aripiprazole compared to other atypical neuroleptics. ${ }^{11,26}$ Efficacy on cognitive functions is heralded but further clinical evidence is needed.

Despite normal fluctuations in motor symptoms occurring in HD along the course of the disease, the benefits we obtained in these three patients over the 12 months follow-up may be considered an indicator of the efficacy of aripiprazole in HD. Further evidence clearly awaits confirmation from a larger study. Notwithstanding this caveat, considering aripiprazole's known dopamine stabilizing properties, the beneficial symptomatic effects we report on both motor and behavioural manifestations suggest investigating whether this drug might benefit voluntary movements, other than chorea. If so, considering that in one of our patients it improved apathy, a behavioural disturbance severely affecting patients' independence in mild-to-advanced HD stages, aripiprazole might be an interesting novel symptomatic option that could be combined with other drugs specifically acting on chorea, such as tetrabenazine. ${ }^{27}$

In conclusion, our case reports suggest that aripiprazole is well tolerated, remarkably improving some of the motor and behavioral symptoms in patients affected by HD. Randomized, controlled, long-term studies are warranted to further investigate the effectiveness of this atypical neuroleptic in the symptomatic treatment in patients with HD. 


\section{Disclosure}

The authors report no conflicts of interest in this work.

\section{References}

1. Adam OR, Jankovic J. Symptomatic treatment of Huntington disease. Neurotherapeutics. 2008;5:181-197.

2. Bonelli RM, Hofmann P. A systematic review of the treatment studies in Huntington's disease since 1990. Expert Opin Pharmacother. 2007;8:141-153.

3. Roos RA, Buruma OJ, Bruyn GW, Kemp B, van der Velde EA. Tiapride in the treatment of Huntington's chorea. Acta Neurol Scand. 1982;65:45-50.

4. Parsa MA, Szigethy E, Voci JM, Meltzer HY. Risperidone in treatment of choreoathetosis of Huntington's disease. J Clin Psychopharmacol. 1997; 17:134-135.

5. Madhusoodanan S, Brenner R. Use of risperidone in psychosis associated with Huntington's disease. Am J Geriatr Psychiatry. 1998;6:347-349.

6. Dallocchio C, Buffa C, Tinelli C, Mazzarello P. Effectiveness of risperidone in Huntington chorea patients. J Clin Psychopharmacol. 1999; 19:101-103.

7. Erdemoglu AK, Boratav C. Risperidone in chorea and psychosis of Huntington's disease. Eur J Neurol. 2002;9:182-183.

8. Duff K, Beglinger LJ, O'Rourke ME, Nopoulos P, Paulson HL, Paulsen JS. Risperidone and the treatment of psychiatric, motor, and cognitive symptoms in Huntington's disease. Ann Clin Psychiatry. 2008;20:1-3.

9. Squitieri F, Cannella M, Piorcellini A, Brusa L, Simonelli M, Ruggieri S. Short-term effects of olanzapine in Huntington disease. Neuropsychiatry Neuropsychol Behav Neurol. 2001;14:69-72.

10. Bonelli RM, Mahnert FA, Niederwieser G. Olanzapine for Huntington's disease: an open label study. Clin Neuropharmacol. 2002;25:263-265.

11. Newcomer JW. Second-generation (atypical) antipsychotics and metabolic effects: a comprehensive literature review. CNS Drugs. 2005;19(Suppl 1):1-93.

12. Lieberman JA. Aripiprazole. In: Schatzberg AF, Nemeroff CB, editors. The American Psychiatric Publishing Textbook of Psychopharmacology, 3rd ed. Washington DC and London UK: American Psychiatric Publishing. 2004. p. 407-494.

13. Gardner DM, Baldessarini RJ, Waraich P. Modern antipsychotic drugs: a critical overview. CMAJ. 2005;172:1703-1711.
14. Kane JM, Carson WH, Saha AR, et al. Efficacy and safety of aripiprazole and haloperidol versus placebo in patients with schizophrenia and schizoaffective disorder. J Clin Psychiatry. 2002;63:763-771.

15. Pigott TA, Carson WH, Saha AR, Torbeyns AF, Stock EG, Ingenito GG; Aripiprazole Study Group. Aripiprazole for the prevention of relapse in stabilized patients with chronic schizophrenia: a placebo-controlled 26-week study. J Clin Psychiatry. 2003;64:1048-1056.

16. Huntington Study Group. Unified Huntington's Disease Rating Scale: reliability and consistency. Mov Disord. 1996;11:136-142.

17. Beck AT, Ward CH, Mendelson M, Mock J, Erbaugh J. An inventory for measuring depression. Arch Gen Psychiatry. 1961;4:53-63.

18. Ciammola A, Sassone J, Squitieri F, et al. Aripiprazole in Huntington's disease: A first case report. Editors Movement Disorders. Proceeding of the Movement Disorder Society's Eleventh International Congress of Parkinson's Disease and Movement Disorders; 2007 June 3-7; Istanbul, Turkey. 2007;22(Suppl 16):S27.

19. Shapiro DA, Renock S, Arrington E, et al. Aripiprazole, a novel atypical antipsychotic drug with a unique and robust pharmacology. Neuropsychopharmacology. 2003;28:1400-1411.

20. Burris KD, Molski TF, Xu C, et al. Aripiprazole, a novel antipsychotic, is a high-affinity partial agonist at human dopamine D2 receptors. J Pharmacol Exp Ther. 2002;302:381-389.

21. Van Vugt JPP, Siesling S, Vergeer M, van der Velde EA, Roos RA. Clozapine versus placebo in Huntington's disease: a double blind randomised comparative study. J Neurol Neurosurg Psychiatry. 1997;63:35-39.

22. Chrzanowski WK, Marcus RN, Torbeyns A, Nyilas M, McQuade RD. Effectiveness of long-term aripiprazole therapy in patients with acutely relapsing or chronic, stable schizophrenia: a 52-week, open-label comparison with olanzapine. Psychopharmacology (Berl). 2006;189:259-266.

23. Meltzer HY. The role of serotonin in antipsychotic drug action. Neuropsychopharmacology. 1999;21(Suppl 2):106-115.

24. Millian MJ. Improving the treatment of schizophrenia: focus on serotonin (5-HT)(1A) receptors. J Pharmacol Exp Ther. 2000;295:853-861.

25. Jordan S, Koprivica V, Chen R, Tottori K, Kikuchi T, Altar CA. The antipsychotic aripiprazole is a potent, partial agonist at the human 5-HT1A receptor. Eur J Pharmacol. 2002;441:137-140.

26. McQuade RD, Stock E, Marcus R, et al. Comparison of weight change during treatment with olanzapine or aripiprazole: results from a randomized, double-blind study. J Clin Psychiatry. 2004;65(Suppl 18):47-56.

27. Huntington Study Group. Tetrabenazine as antichorea therapy in Huntington disease: a randomized controlled trial. Neurology. 2006; $66: 366-372$. 